\title{
Prevalence of altered cervical cytological pattern: Aretrospective study in females visiting tertiary care hospital
}

\author{
Gidwani RK ${ }^{1}$, Goswami FJ ${ }^{2}$, Shah NV$^{3}$, Srilakshmi HP ${ }^{4}$, Ramchandani GK ${ }^{5}$, Chawada BL $^{6}$ \\ ${ }^{1}$ Dr. Roopam K Gidwani, Assistant Professor, Pathology, ${ }^{2}$ Dr. Falguni J Goswami, Tutor, Pathology, ${ }^{3}$ Dr. Nirali V Shah, \\ Tutor, Pathology, ${ }^{4}$ Dr. HP Srilakshmi, Associate Professor, Pathology, ${ }^{5}$ Dr. Gena K Ramchandani, Associate Professor, \\ Pathology, ${ }^{6}$ Dr. Bansari L Chawada, Community Medicine, Assistant Professor, Community Medicine; all authors are \\ affiliated with Medical College, Baroda, Gujarat, India.
}

Corresponding Author: Dr. Roopam K Gidwani, Assistant Professor, Pathology, Medical College, Baroda, Gujarat, India. E-mail: roopamgidwani@gmail.com

\begin{abstract}
Background: Cervical cancer is one of the major causes of morbidity and mortality in India. Pap smear is a simple, noninvasive, cost-effective and sensitive tool to detect various non-neoplastic and neoplastic lesions of cervix. The objective of this study was to estimate the prevalence of cervical cytological pattern in a tertiary care centre; by using conventional Papanicolaou (Pap) smears for the screening of inflammatory, premalignant and malignant lesions of the cervix. Methods: This cross-sectional study is based on 574 patients who attended the out-patient Department of Obstetrics and Gynecology, during the period between Jan 2015 to Feb 2017. Pap smears were prepared from patients presenting with complaints like vaginal discharge, post-coital bleeding, inter-menstrual bleeding, dyspareunia, and pain in lower abdomen. Conventional Papanicolaoustained smears were classified as per Bethesda 2001 nomenclature. Results: Prevalence of altered cervical cytological pattern was $75.59 \%$ amongst females visiting hospital. A total of 574 cervical pap smears were studied, out of which 66 were inadequate. Out of 508 cases, 448 cases were of NILM [including 324 (63.78\%) inflammatory lesions and $124(24.41 \%)$ normal smears] and $60(11.81 \%)$ cases of epithelial lesions. The epithelial lesions prevalence rate was ASCUS (5.7\%), LSIL (1.4\%) and HSIL (1.4\%), AGUS (0.78\%), SCC (0.6\%) and endometrial carcinoma $(0.2 \%)$. Conclusions: This study shows relatively high prevalence of epithelial abnormalities with increasing age, parity, women with clinical lesions on per speculum findings. Malignancy was more common in sixth and seventh decade and intraepithelial lesions/dysplasia was seen mostly in fourth and fifth decade. Inflammatory lesions were more common in younger age group. Pap smear should be advised as a routine screening procedure; as it is a simple, cheap, safe and practical diagnostic tool for early detection of cervical cancer in high risk group population. It also helps in diagnosis of inflammatory lesions including the identification of causative organism and atrophic changes.
\end{abstract}

Keywords: Bethesda system, Papanicolaou smear, Cervical screening, Squamousintraepithelial lesion (SIL)

\section{Introduction}

Cervical cancer is the most common cancer among women after breast and colorectal cancer in the world, but in India and other developing countries cervical cancer is the leading cause of mortality and morbidity [1]. The identified risk factors are persistent infection with Human Papilloma virus, early age at marriage, multi parity, less spacing between pregnancies, low socio-economic status, prolonged use of oral contraceptives and smoking [2]. Gynaecological health issues being a socially sensitive health issue, it affects health seeking behaviour of patients. Women in

Manuscript received: $14^{\text {th }}$ May 2018

Reviewed: $24^{\text {th }}$ May 2018

Author Corrected: $30^{\text {th }}$ May 2018

Accepted for Publication: $6^{\text {th }}$ June 2018 developing countries usually present to the clinic only when they have symptoms such as pain, discharge per vaginum, and abnormal bleeding per vaginum [1]. The Papanicolaou (Pap) test is a screening test performed using the cells from the uterine cervix. This test was introduced by George Papanicolaou as a cervical pathology screening test in 1941[3]. Pap smear is a simple, non-invasive, cost-effective and sensitive tool available to detect various non-neoplastic and neoplastic lesions of cervix [4].

Papanicolaou cytological testing (Pap smear) permits cervical lesions to be detected before they become cancerous, effectively reducing the incidence of cervical 


\section{Original Research Article}

cancer by $75 \%$ - $90 \%$. Cancer of cervix is readily preventable, by early detection and appropriate timely treatment of its precursor lesions by simple Pap screening test. Though Pap smear is a routine screening test, the overall sensitivity in detection of high grade squamous intraepithelial lesion (HSIL) is $70-80 \%$ [2].

Though pap test plays a stellar role in detection of carcinoma and precancerous lesions, its role in diagnosis of infective inflammatory conditions including the identification of causative organisms, hormone related benign epithelial changes and changes due to therapeutic agents is no less successful.

Originally, the term Pap smear was used for smears made out of posterior fornix material for purpose of detection of cancer and precancerous lesions. But presently, the term is used for smears made from material collected from vagina, endocervical canal, ectocervix or vaginal vault [5].

The risk of cervical cancer remains high among patients visiting clinics and it will be an opportunity to diagnose them early with simple screening tool like Pap smear. Early detection of epithelial abnormalities helps in early treatment of dysplastic epithelial changes and can prevent invasive cervical carcinoma.

The objective of this study was to estimate the prevalence of cervical cytological pattern in females visiting tertiary care hospital. Another objective was to categorize the cytological pattern for the screening of inflammatory, premalignant and malignant lesions of the cervix.

\section{Methodology}

Place of study: Tertiary health care hospital attached with Government Medical College, in Central Gujarat; on patients who attended the outpatient department (OPD) of Obstetrics and Gynaecology (OBGY).

Type of study: Thiscross-sectional study is based on 574 patients who attended the outpatient Department of Obstetrics and Gynaecology, during the period between Jan 2015 to Feb 2017.

Sampling methods and collection: A detailed history and symptoms along with parity and last menstrual period were recorded by the concerned gynecologist and local examination was done to check any lesion.

After obtaining informed consent while maintaining privacy, smears were collected by consultants of gynecology department. Samples were collected from ectocervix as well as endocervix.

Two smears were prepared for each case, properly labeled, fixed in $95 \%$ ethyl alcohol immediately and sent to pathology department for Pap staining.

The smears were stained by Papanicolaou method; screened and reported by two pathologists independently according to Bethesda system, 2001 [6].

The results given by two pathologists were matched and if any discrepancy was found, it was again sent to two pathologists independently for final match of results.

Inclusion criteria: Pap smears were collected from patients presenting with complaints like leucorrhoea, post-coital bleeding, inter-menstrual bleeding, dyspareunia and pain in lower abdomen; as well as those who had no complaints and had come for routine cervical screening.

Exclusion criteria: Total 66 "inadequate or unsatisfactory smears for evaluation" cases were excluded from the study.

Reporting of smears: The Pap smears were screened and reported by two pathologists independently according to Bethesda system, 2001 [6].

The results given by two pathologists were matched and if any discrepancy was found, it was again sent to two pathologists independently for final match of results.

Evaluation of the cervical cells was done using the Bethesda System, 2001 as follows: 
Original Research Article

\section{Specimen adequacy}

- Satisfactory for evaluation

- Presence or absence of endocervical or transformation zone components or

- Other quality indicators such as partially obscuring blood or inflammation

- Unsatisfactory for evaluation (specify reason)

\section{General categorization(optional)}

- Negative for intraepithelial lesion or malignancy

- Epithelial cell abnormality

- Other

\section{Interpretation/result}

- Negative for intraepithelial lesion or malignancy

- Organisms

- Trichomonas vaginalis

- Fungal organisms morphologically consistent with Candida spp.

- Shift in flora suggestive of bacterial vaginosis

- Bacteria morphologically consistentwithActinomyces spp.

- Cellular changes consistent with Herpes simplexvirus.

o Other non-neoplastic findings

- Reactive cellular changes

- Glandular cells status post hysterectomy

- Atrophy

- Epithelial cell abnormalities

- Squamous cell

- Atypical squamous cells (ASC) Atypical squamous cells of undetermined significance (ASC-US) ASC, cannot exclude High grade squamous intraepithelial lesion(ASC-H)

- Low grade squamous intraepithelial lesion (LSIL) encompassing: human papilloma virus (HPV)/mild dysplasia/CIN 1

- High grade squamous intraepithelial lesion (HSIL) encompassing: moderate and severe dysplasia, CIS/CIN 2 and CIN3 with features suspicious for invasion (if invasion is suspected)

- Squamous cell carcinoma

- Glandular cell

- Atypical glandular cells (AGC)

- Atypical glandular cells, favour neoplastic

- Endocervical adenocarcinoma in situ (AIS)

- Adenocarcinoma

- Other malignant neoplasms

Statistical methods: Age, clinical presentation and pathological diagnoses of each case were recorded. The data was entered in MS Office 2007and analyzed.

\section{Results}

A total of 574 smears were studied during the duration between January 2015 to Feb 2017, out of these, 66 smears were inadequate or unsatisfactory due to blood/mucus and were excluded from our study. Out of 508 Pap smears studied there were 448 cases of NILM [including 324 (63.78\%) Inflammatory Lesions and 124 (24.41\%) normal smears] and 60 $(11.81 \%)$ cases of epithelial lesions.

Among patients with abnormal Pap findings, cervical erosion, leucorrhoea, inter-menstrual bleeding, vaginitis and cervical hypertrophy were the most common clinical findings observed. 
Table-1: Distribution of participants according to Cytological findings $(\mathbf{n}=508)$.

\section{Original Research Article}

\begin{tabular}{|c|c|c|}
\hline Sr No & Cytological findings & Frequency no (\%) \\
\hline \multirow{2}{*}{1} & NILM & \\
\cline { 2 - 3 } & Normal smears & $124(24.41 \%)$ \\
\cline { 2 - 3 } & Inflammatory Lesions & $324(63.78 \%)$ \\
\hline 2 & Epithelial lesions & $60(11.81 \%)$ \\
\hline & Total & $\mathbf{5 0 8}(\mathbf{1 0 0} \%)$ \\
\hline
\end{tabular}

Based on cytological findings, more than half $324(63.78 \%)$ cases were inflammatory lesions, $124(24.41 \%)$ were normal smears and $60(11.81 \%)$ cases were of epithelial lesions. (Table 1)

Table-2: Age wise distribution of various inflammatory and epithelial lesions of cervix $(n=508)$.

\begin{tabular}{|c|c|c|c|c|c|c|c|}
\hline & \multicolumn{7}{|c|}{ Age group (Years) } \\
\hline Cytological findings & $15-30$ & $31-40$ & $41-50$ & $51-60$ & $61-70$ & $\geq 71$ & Total (\%) \\
\hline Cervicitis & 95 & 138 & 63 & 12 & 2 & 0 & $310(60.22 \%)$ \\
\hline Trichomonas Vaginalis & 2 & 2 & 1 & 0 & 0 & 0 & $5(0.98 \%)$ \\
\hline Atrophy & 0 & 0 & 1 & 1 & 3 & 2 & $7(1.4 \%)$ \\
\hline Bacterial vaginosis & 0 & 1 & 0 & 0 & 0 & 0 & $1(0.2 \%)$ \\
\hline Herpes simplex & 1 & 0 & 0 & 0 & 0 & 0 & $1(0.2 \%)$ \\
\hline Normal smears & 37 & 55 & 22 & 7 & 2 & 1 & $124(24.409 \%)$ \\
\hline ASCUS & 3 & 8 & 15 & 1 & 2 & 0 & $29(5.7 \%)$ \\
\hline AGUS & 0 & 1 & 3 & 0 & 0 & 0 & $4(0.78 \%)$ \\
\hline ASCUS/LSIL & 3 & 1 & 1 & 1 & 0 & 0 & $6(1.18 \%)$ \\
\hline LSIL & 2 & 3 & 1 & 1 & 0 & 0 & $7(1.4 \%)$ \\
\hline HSIL & 0 & 2 & 1 & 2 & 2 & 0 & $7(1.4 \%)$ \\
\hline SCC & 0 & 2 & 2 & 1 & 0 & 0 & $5(1 \%)$ \\
\hline Adenocarcinoma & 0 & 0 & 0 & 0 & 0 & 0 & $0(0 \%)$ \\
\hline HSIL/SCC & 0 & 1 & 0 & 0 & 0 & 0 & $1(0.2 \%)$ \\
\hline Endometrial Ca & 0 & 1 & 0 & 0 & 0 & 0 & $1(0.2 \%)$ \\
\hline Total & $\mathbf{1 4 3}$ & $\mathbf{2 1 5}$ & $\mathbf{1 1 0}$ & $\mathbf{2 6}$ & $\mathbf{1 1}$ & $\mathbf{3}$ & $\mathbf{5 0 8}(\mathbf{1 0 0 \% )}$ \\
\hline
\end{tabular}

As stated in Table 2, inflammatory lesions were most of the time found among women of age group 15 to 50 years of age. More than half $(60.22 \%)$, of inflammatory lesions were diagnosed as nonspecific cervicitis, followed by atrophic changes $(1.4 \%)$, Trichomonas vaginalis $(0.98 \%)$, Herpes simplex $(0.2 \%)$ and bacterial vaginosis $(0.2 \%)$. More than one fifth of patients $(24.41 \%)$ were categorized into normal smears, and epithelial lesions were reported as ASCUS $(5.7 \%$ of patients), LSIL ( $1.4 \%$ of patients) and HSIL ( $1.4 \%$ of patients), AGUS ( $0.78 \%$ of patients), SCC ( $0.6 \%$ of patients) and endometrial carcinoma ( $0.2 \%$ of patients).

\section{Discussion}

Cancer of cervix is readily preventable when effective programmes are conducted to detect and treat its precursor lesions. There is a long latent phase which precedes the invasive malignancy; during this period premalignant lesions can be detected. This gives the benefit of conducting screening for carcinoma cervix in early stages [4]. Early detection of epithelial abnormalities helps in early treatment of dysplastic epithelial changes, which can prevent invasive cervical carcinoma [7]. The incidence of cervical cancer has decreased more than $50 \%$ in the past 30 years because of widespread screening with cervical cytology.The role 
of HPV in development of cervical cancer is proved beyond doubt. If Pap screening is associated with HPVDNA testing than we can increase the sensitivity. World Health Organization (1992) recommended screening every woman once in her lifetime at 40 years $[8,9]$. In countries like India with predominant rural population, having low socioeconomic status, marriage at an early age and poor medical facility; it is a major challenge to formulate a screening program that is easily available, within existing resources, to a large section of society [8].

We have studied a total of 574 smears during the duration between January 2015 to Feb 2017; out of these, 66 smears were inadequate or unsatisfactory due to blood/mucus. Proportion of inadequate samples were $11.5 \%$ in our set up while two separate studies done by Rawat K et al (16.1\%) and Gupta $\mathrm{S}$ et al reports similar findings. [10,11].The unsatisfactory rate is an important quality assurance indicator in cervical cytology as it identifies women who are being inadequately screened. Sampling technique skills, storage or transportation could be the reason for higher inadequate smear proportion.Regular training of healthcare personnel about proper preparation of pap smears and feed back is necessary, in our setup.

The age of patients ranged from 22 to 77 years in our study. Our study showed maximum number of patients in the $4^{\text {th }}$ decade $(42.32 \%)$, followed by $2^{\text {nd }}$ decade $(28.14 \%)$, and $5^{\text {th }}$ decade $(21.65 \%)$. Similar findings were documented in other studies. Babu et al found $32.57 \%$ of the study population in 5th decade, followed by $28.55 \%$ in $4^{\text {th }}$ decade and $20.14 \%$ in $3^{\text {rd }}$ decade. Bal et alfound maximum number of cases in the 4 th decade $(45.3 \%)$, followed by $33.3 \%$ in $3^{\text {rd }}$ decade, $17.7 \%$ in $5^{\text {th }}$ decade. Bamanikar et al found maximum number of cases in the 4 th decade $(32.68 \%)[1,4,12]$.

Our study shows that most common clinical complaints were cervical erosion followed by leucorrhoea, intermenstrual bleeding, vaginitis and cervical hypertrophy. Similar pattern of findings were reported by Sharma P, et al. in a community based study on cervical cancer screening program among women of Delhi [13]. Another study done by Sandhya Rani et al among 500 women showed similar clinical findings [7]. Present study emphasized the significance of vaginal discharge and its association with neoplastic changes in the cervix. The results correspond with many previous studies $[1,4]$.

Out of 508 Pap smears studied, 324 (63.78\%) smears were inflammatory; among inflammatory smears

\section{Original Research Article}

nonspecific cervicitis (non-specific inflammation) $(60.22 \%)$ was the pre-dominant finding. Pap smears of inflammatory lesions showed only neutrophils and bacteria on the slide with no atypical cells or dysplasia, indicating the importance of proper hygiene maintenance in prevention of cervical epithelial lesions.

Another important observation of our study was presence of Trichomonas vaginalis infection in 5 $(0.98 \%)$ cases and Herpes simplex in one case. It suggests that in all cases of inflammatory smears, full microbiological workup should be done. Study done by Babu et al found $28.47 \%$ cases had non-specific inflammation, $15.51 \%$ had Trichomonas vaginalis infection and $4.2 \%$ had bacterial vaginosis.

Bamanikaret alfound 68.93\%non-specific inflammation, $0.54 \%$ Trichomonas vaginalis. The study by $\mathrm{Bal}$ et al [8] showed $71.3 \%$ non-specific inflammation and $0.3 \%$ Trichomonas infection. Trichomonas infection is a sexually transmitted infection. Presence of sexually transmitted diseases (STD) is an established risk factor for cervical carcinoma. This emphasizes the necessity of follow up of these patients and periodic PAP smear screening $[1,4,12]$.

Epithelial cell abnormalities, that is the total of ASCUS, LSIL, HSIL and SCC were seen in $60(11.81 \%)$ cases in our study as compared to other studies where the proportion of epithelial abnormality varies between 1.5 $-12 \%[1,8,10,14,15]$. Our study documents $5.7 \%$ of patients as ASCUS,to be the most common epithelial cell abnormality. Results from other studies done by Saha D et al (1.74\%) and by Rawat et al (1.3\%) documents lower proportions $[8,10]$. Smears showing LSIL and HSIL were low (1.4\%) in current study, similarly it was seen in lower proportion in other studies $[1,4]$. AGUS was rare finding $(0.78 \%)$, which was similar rare finding in other studies $[9,10,11]$.

In current study, LSIL was commonly found in $4^{\text {th }}$ and $5^{\text {th }}$ decade, and HSIL in $5^{\text {th }}, 6^{\text {th }}$ and $7^{\text {th }}$ decade and SCC in $5^{\text {th }}$ and $6^{\text {th }}$ decade. The incidence of HSIL and SCC was increased in the above 50 years age group indicating the gradually increasing incidence of malignancy with age. These results are in accordance with the studies of Bal et al, Gupta et al and Rawat et al $[4,10,11]$. We also compared the results obtained in this study with few other studies.

\section{Conclusions}

Prevalence of altered cervical cytological pattern was $75.59 \%$ amongst females visiting hospital. This study 


\section{Original Research Article}

shows relatively high prevalence of epithelial abnormalities with increasing age, parity, women with clinical lesions on per speculum findings. Malignancy was more common in sixth and seventh decade and intraepithelial lesions/dysplasia was seen mostly in fourth and fifth decade. Papsmearalso has a greater role in diagnosis of inflammatory lesions including the identification of causative organisms and atrophic changes. We propose that larger studies are required to estimate the pattern of cervical cytological abnormalities along with detection of common HPV strains in cervical cancer in Indian population, as this knowledge would be useful for prevention of HPV infection either by vaccines or future targeted therapy.

Recommendations: Microbiological investigations are also recommended for all inflammatory cervical lesions. More effective systems for sample collection and transport could be developed to decrease inadequate smear proportion. There is definite scope of future research to measure socio-demographic associations with altered cytological patterns among females.

Contribution of this study: This study contributes to assessing current levels of cervical screening in our tertiary care hospital. Though PAP smear examination is primarily aimed at diagnosing the premalignant conditions of cervix, we can diagnose various infective and non-infective benign lesions of cervix also. Most of these benign lesions are easily treatable. This study will help to know epidemiology of patients attending our hospital and thus would be helpful to form local preventive measures.

Acknowledgements: We acknowledge Dr. A T Leuva, Dean, Medical College Baroda, Dr V S Mazumdar, Professor and Head, and Prof. R K Baxi, Professor, Department of PSM, Medical College Baroda. Our special thanks to Dr. Kalpita Shringarpure. We are also thankful to the consultants of OBGY department of our institute. Last but not the least, special thanks to the patients and cytology staff for the support.

Funding: Nil, Conflict of interest: None initiated Permission from IRB: Yes

\section{References}

1.Bamanikar SA, Baravkar DS, Chandanwale SS andDapkekar P, Study of Cervical Pap smears in aTertiaryHospital. Indian Medical Gazette. 2014: 250254.

2.Thirumurugan. P, Premila.E, Suresh Kanna. K, Study of early detection of cervical cancer by PAP's smear in selected setting of Puducherry.Asia Pacific Journal of Research. Vol: I. Issue XXXIV, December 2015: 156- 160.

3. VaghelaBV; VaghelaVK.; SantwaniPM. Analysis of abnormal cervical cytology inPapanicolaou smears at tertiary care center - A retrospective study. International Journal of Biomedical and Advance Research, [S.1.], v. 5, n. 1, p. 47-49, Jan. 2014. ISSN 2229-3809.

4. Bal MS, Goyal R, Suri AK, Mohi MK. Detection ofabnormalcervical cytology in Papanicolaou smears. J Cytol2012;29:45-7.

5. Anderson and Jones: false positive cervicovaginal cytology. acta cytol41(6):267,1997.

6. Solomon D, Davey D, Kurman R et al. The 2001 Bethesda system: Terminology for reporting results of cervical cytology. JAMA.2002;287:2114-9.

7. B. Sandhya Rani. Cervical Pap Smear Study for Screening of Pre-Cancerous Conditions of Cervix. IAIM, 2018; 5(1): 138- 144.

8. Saha D, Ghosh S, Nath S, Islam H. Utility of Pap smear screening for prevention of cervical cancer- A 3yrs studyfrom rural Tripura - Anortheastern state of India. Int J Med and Dent Sci. 2017; 6 (2): 14561461.

9. Patel MM, Pandya AN, Modi J. Cervical papsmear study and its utility in cancer screening, to specify the strategy for cervical cancer control. National Journal of Community Medicine. 2011;2(1):49-51.

10. Rawat $\mathrm{K}$ etal.A study of cytological pattern of cervical papanicolaousmears in western Rajasthan, IndiaInt J Reprod Contracept Obstet Gynecol. 2016 Sept; 5 (9):3186-3190.

11. Gupta S, Sodhani P, Halder K, Chachra KL, Singh $\mathrm{V}$, Sehgal A. Age trends in pre-cancerous and cancerous lesions of the uterine cervix in a cytology screening programme: what should be the target age group for a major thrust of screening in resource limited settings? Cytopathology. 2008;19(2):106-10.

12.Anindita Sinha Babu, Manisha Sarkar, Dipanwita Das. Spectrum of cervical lesions in papanicolaousmears examination in a new tertiary care centre.International Journal of Contemporary Medical Research. 2017;4(9):1986- 1990. 


\section{Original Research Article}

13. Sharma P, Rahi M, Lal P.A Community-based Cervical Cancer Screening Program among Women of Delhi using Camp Approach. Indian J Community Med., 2010; 35(1): 86-8.

14. Malpani $G$ et al. Cervical Pap smear study and detection of abnormal epithelial lesions and determination of its accuracy by cytohistological

correlation in patients of tertiary care teaching hospital in central India. Int $\mathbf{J}$ Reprod Contracept Obste Gynecol. 2016;5:2312-6.

15. Tailor HJ, Patel RD, Patel PR, Bhagat VM. Study of cervical pap smears in a tertiary care hospital of south Gujarat, India. Int J Res Med Sci. 2016;4:286-288.

\section{How to cite this article?}

Gidwani RK, Goswami FJ, Shah NV, Srilakshmi HP, Ramchandani GK, Chawada BL. Prevalence of altered cervical cytological pattern: Aretrospective study in females visiting tertiary care hospital.Trop J Path Micro 2018;4(2):188-194. doi: 10.17511/jopm.2018.i2.13 